Document downloaded from:

http://hdl.handle.net/10251/33433

This paper must be cited as:

Berenguer, R.; Marco-Lozar, JP.; Quijada, C.; Cazorla-Amoros, D.; Morallón, E. (2012). A comparison between oxidation of activated carbon by electrochemical and chemical treatments. Carbon. 50(3):1123-1134. doi:10.1016/j.carbon.2011.10.025

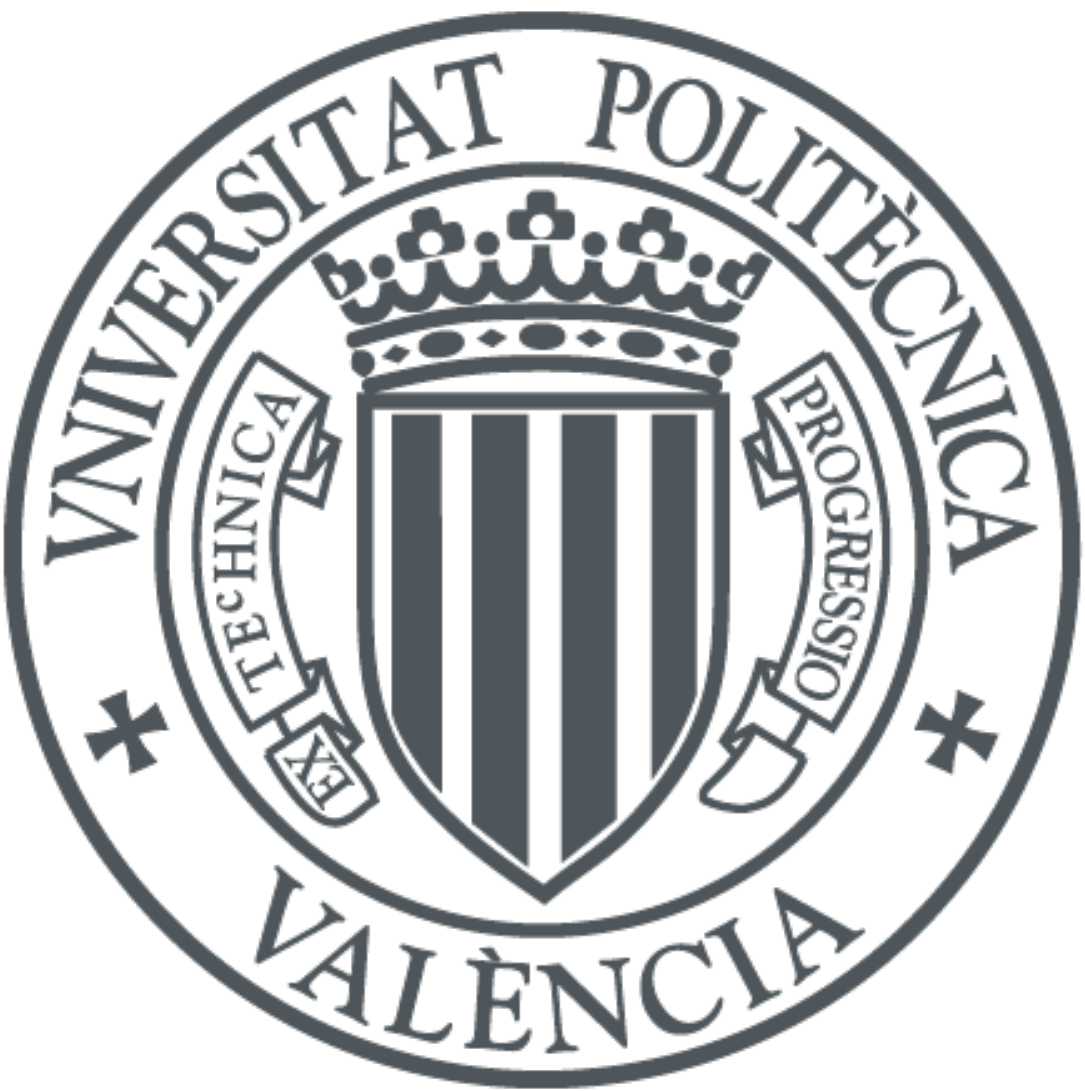

The final publication is available at

http://doi.org/10.1016/j.carbon.2011.10.025

Copyright Elsevier

Additional Information 


\title{
A comparison between oxidation of activated carbon by electrochemical and chemical treatments
}

\author{
R. Berenguer ${ }^{\mathrm{a}}$, J.P. Marco-Lozar ${ }^{\mathrm{b}}$, C. Quijada ${ }^{\mathrm{c}}$, D. Cazorla-Amorós ${ }^{\mathrm{b}}$ and E. Morallón ${ }^{\mathrm{a}}$ \\ ${ }^{a}$ Departamento de Química Física and Instituto Universitario de Materiales. Universidad de \\ Alicante. Apartado 99. E-03080 Alicante. Spain \\ ${ }^{\mathrm{b}}$ Departamento de Química Inorgánica and Instituto Universitario de Materiales. Universidad de \\ Alicante. Apartado 99. E-03080 Alicante. Spain \\ ${ }^{\mathrm{c}}$ Departamento de Ingeniería Textil y Papelera, Universitat Politècnica de València. Pza \\ Ferrándiz y Carbonell, E-03801 Alcoy (Alicante). Spain
}

\begin{abstract}
The anodic oxidation of a granular activated carbon (GAC) in $\mathrm{NaCl}$ solution has been studied. The influence of the electrocatalyst-anode material, applied current and time of treatment on both the surface chemistry and porous texture properties of the GAC has been analyzed. For comparison purposes, the same GAC has been treated with three of the classical chemical oxidants: $\mathrm{HNO}_{3}, \mathrm{H}_{2} \mathrm{O}_{2}$ and $\left(\mathrm{NH}_{4}\right)_{2} \mathrm{~S}_{2} \mathrm{O}_{8}$ at different concentrations and for different times. Results show that the anodic treatment in $\mathrm{NaCl}$ causes a remarkable oxidation of the $\mathrm{AC}$ without modifying significantly its textural properties. TPD profiles and the linear dependence of the amount of $\mathrm{CO}$ - and $\mathrm{CO}_{2}$-evolution against the oxidation level denotes that surface oxygen groups of similar nature and composition are formed anodically, regardless of the anode material. The achieved oxidation degree depends on the different ability of each anode for the electrochemical generation of highly oxidizing chlorine species, and it increases progressively with the applied current and the time of treatment. In general, for similar treatment times, the anodic treatment in
\end{abstract}


$\mathrm{NaCl}$ can produce oxidation degrees much higher than the chemical treatment with $\left(\mathrm{NH}_{4}\right)_{2} \mathrm{~S}_{2} \mathrm{O}_{8}$, which has been found to be the most oxidative chemical studied in this work.

*Corresponding author: Tel: +34-965909590. Fax: +34-965903537. E-mail address: morallon@ua.es (E. Morallón) 


\section{Introduction}

The practical use and applications of activated carbons (ACs) in many industrial fields and technologies are based on their outstanding physicochemical properties, especially the surface area, the porous texture and the surface chemistry. In particular, the relevance of surface oxygen groups (SOGs) in the performance of carbon materials is known for more than 20 years [1-5]. The presence of SOGs on the graphene sheets or edges of carbon materials results in their destabilization, altering their acid-base and electron-donor/-acceptor properties [6,7] and modifying their hydrophobic character [8], conductivity [9], capacitance $[9,10]$, etc. Moreover, upon tailoring surface complexes, affinity towards a wide variety of organic and inorganic compounds can increase and, hence, their performance in the removal/adsorption of some pollutants and in the recovery of metals can be enhanced [2]. In addition, SOGs act as anchoring sites for other functional molecules, which act as ligands, catalysts, or reactants in many important reactions [6]. They can also facilitate the incorporation of other materials, such as metallic or oxide nanoparticles, polymers, etc. [11,12], introducing or remarkably improving some properties.

Considering the huge influence of surface chemistry in the performance of carbon materials, methods allowing the control of both the nature and concentration of surface functional groups for specific applications would be of crucial importance. In general, the different AC properties mainly depend on the precursor nature and the synthesis route, but they can also be modified by a suitable post-treatment step. Although textural properties can be modified by thermal posttreatments, they are usually set by an adequate choice of the activation procedure. On the contrary, post-treatments are mainly used to modify the nature and concentration of SOGs. 
Regarding the surface chemistry, post-treatments of as-received commercial AC or carbonaceous materials after activation consist of oxidation and/or reduction treatments in gas or liquid phase. The various $\mathrm{AC}$ modification techniques and their effects on $\mathrm{AC}$ properties have been the subject of intensive research $[10,13-23]$. The most used techniques for surface chemistry modification have been: (i) heating $\left(500-1000^{\circ} \mathrm{C}\right)$ under inert atmosphere [13-15], to selectively remove some of these functions, and (ii) the chemical post-treatment in liquid phase, using oxidants such as $\mathrm{HNO}_{3}, \mathrm{H}_{2} \mathrm{O}_{2},\left(\mathrm{NH}_{4}\right)_{2} \mathrm{~S}_{2} \mathrm{O}_{8}$ [13-19], to increase the concentration of SOGs. Other methods using oxidizing gases $\left(\mathrm{O}_{2}, \mathrm{O}_{3}, \mathrm{Cl}_{2}\right.$, etc.) [19-22] or oxygen plasma [23] have been also introduced.

However, in spite of being widely studied and applied, conventional chemical and thermal posttreatment methods are not suitable enough for controlling and modifying easily and selectively the surface chemistry of carbon materials. This could be due not only to the more complex experimental system and handling derived from using gases, harmful agents and/or high temperatures, but also, to the fact that neither the oxidizing power of a given oxidative agent nor the extent of oxidation reactions can be easily controlled and modulated. As a consequence, and unlike the advanced state of the art on optimization and tailoring of the porous structure of carbon materials [24], it is necessary to carry out much more exhaustive and detailed research on methods and tools for a higher control of the concentration and nature of SOGs in carbon materials.

The electrochemical method [25-32] has emerged as a promising technique for the modification of the surface chemistry of carbon materials in aqueous and organic solvents, because it presents several advantages when compared to conventional methods: mainly, (i) the treatment can be immediately interrupted and (ii) can be run at room temperature and atmospheric pressure; (iii) the reaction conditions can be very precisely reproduced; and (iv) oxidation and reduction 
processes are more selective and easily controlled by means of the proper setting of the applied current or electrode potential.

The electrochemical modification of a commercially-available granular AC has been recently studied in our research group. The influence of different electrochemical variables, such as the electrode polarity (anodic or cathodic), the applied current and the type of electrolyte was analyzed in detail [30]. In particular, it was observed that the anodic treatment in $\mathrm{NaCl}$ results in a high surface oxidation degree, which could be comparable to that of a traditional chemical oxidation. Nevertheless, the efficiency and performance of the different modification methods cannot be directly compared to each other if the modified carbon materials are different. Comparisons are necessary not only to demonstrate the real feasibility of new alternative methods but also to determine the suitability of a given AC modification method for the control of surface chemistry for specific applications.

In the literature on surface chemistry modification, some contributions on the comparison of different modification methods for the same AC carbon material can be found [12,14,17-20], but little work on comparison including the electrochemical oxidation technique has been reported to date [25-27]. Barton et al. [27] used activated carbons whereas the other authors [25,28] used conductive carbon materials. Shao et al. [26] studied the electrochemical oxidation of carbon black and carbon nanotubes in sulphuric acid in similar conditions than those encountered in low temperature fuel cells in order to analyze the stability of the carbon materials as support of the electrocatalysts. Instead, Barton et al. [27] estimated the anodic oxidation degree of a granular $\mathrm{AC}$ in a $0.5 \mathrm{M} \mathrm{K}_{2} \mathrm{SO}_{4}$ solution, at two constant currents and during different periods of time. It was found that a controlled formation of low levels of oxidation can be reached by the anodic 
process, but very long periods of time are necessary to achieve levels of surface oxidation comparable to those produced by chemical oxidation.

In order to further study new approaches on tailoring the surface chemistry of carbon materials, this work presents a comparative study between the treatments of the same granular AC material by conventional chemical modifications in liquid phase and through anodic oxidation in $\mathrm{NaCl}$, this latter being the most oxidizing electrolyte among the various electrolytes tested by our group [30]. The influence of the applied current, the anode nature and time, in the case of the electrochemical method, and the effect of oxidant concentration or oxidation time, in the chemical one, on both the surface chemistry and textural properties of the AC have been analyzed. The comparison is based on the concentration of groups introduced after the modification treatment, the kinetics of the processes and the control of oxidation degree.

\section{Experimental}

\subsection{Electrochemical oxidation of activated carbon.}

The electrochemical modification of a commercial granular activated carbon (GAC) has been carried out anodically in a divided filter-press electrochemical cell. The detailed experimental conditions for a typical electrochemical modification process have been previously described [30]. Briefly, $2 \mathrm{~g}$ of the original washed GAC were galvanostatically treated at $0.2,0.5$, and 1.0

A for $3 \mathrm{~h}$, in a flowing $2 \mathrm{wt} \% \mathrm{NaCl}$ solution $\left(200 \mathrm{~cm}^{3}\right)$, with 4 different anodes: $\mathrm{Ti} / \mathrm{SnO}_{2}-\mathrm{Sb}-\mathrm{Pt}$, $\mathrm{Ti} / \mathrm{RuO}_{2}, \mathrm{Ti} / \mathrm{Co}_{3} \mathrm{O}_{4}$ and $\mathrm{Ti} / \mathrm{Pt}$, prepared by the conventional thermal decomposition method [3436]. A steel electrode was used as the cathode and the area of all electrodes was $20 \mathrm{~cm}^{2}$. For the analysis of time influence, $\mathrm{Ti} / \mathrm{RuO}_{2}$ was selected as the anode and experiments were performed for 1,3 and $5 \mathrm{~h}$. 
For the preparation of the electrolyte solution, distilled water and analytical grade sodium chloride (Merck) were used. The commercial GAC studied in this work was provided by Waterlink Suctliffe Carbons (207A, $\mathrm{pH}_{\mathrm{PZC}}=9$, Mesh: $\left.12 \times 20\right)$ and it is referred to as $\mathrm{W}$.

The anodically modified AC samples will be referred to in the text as a compound name including the letter $\mathrm{W}$, referring to the $\mathrm{AC}$ supplier (Waterlink); the simplified name of the employed anode: $\mathrm{SnO}_{2}, \mathrm{RuO}_{2}, \mathrm{Co}_{3} \mathrm{O}_{4}$ or $\mathrm{Pt}$; the letter a to denote an anodic treatment; a number indicating the applied constant current $(0.2 ; 0.5$ or $1.0 \mathrm{~A})$ and the abbreviation of $\mathrm{Cl}^{-}$, referring to $\mathrm{NaCl}$ electrolyte solution. In the case of the study on time influence, the nomenclature also includes the number of hours of the experiment (1h, 3h or 5h). For example, the label $\mathrm{WSnO}_{2} \mathrm{a} 0.2 \mathrm{Cl}^{-}(3 \mathrm{~h})$ refers to a GAC sample supplied by Waterlink, that was subjected to anodic treatment at $0.2 \mathrm{~A}$ in $2 \mathrm{wt} \% \mathrm{NaCl}$ electrolyte by using an $\mathrm{SnO}_{2}$-type anode for a total electrolysis time of 3 hours.

\subsection{Chemical oxidation of activated carbon.}

Chemical treatments of GAC were carried out in ground glass stoppered flasks, under magnetic stirring, with three oxidizing agents: $\mathrm{HNO}_{3}, \mathrm{H}_{2} \mathrm{O}_{2}$ and $\left(\mathrm{NH}_{4}\right)_{2} \mathrm{~S}_{2} \mathrm{O}_{8}$. The ratio of carbon mass $(\mathrm{g})$ to solution volume $(\mathrm{mL})$ was always $1 / 10$. In the case of nitric acid, carbon samples were put in contact with differently concentrated solutions: 23,35 and $65 \%$ at room temperature for $2 \mathrm{~h}$. Oxidation with hydrogen peroxide was also performed with three different concentrations: 10, 20 and $33 \%$. In this case, however, solutions were boiled and the contact time was extended until total evaporation. For the third chemical reagent, a $\left(\mathrm{NH}_{4}\right)_{2} \mathrm{~S}_{2} \mathrm{O}_{8}$-saturated $1 \mathrm{M} \mathrm{H}_{2} \mathrm{SO}_{4}$ solution was employed (solubility in water at $20{ }^{\circ} \mathrm{C}$ is $620 \mathrm{~g} / \mathrm{L}$ ) for: 2,5 and $24 \mathrm{~h}$. The oxidative chemicals and experimental conditions have been chosen in this way because they have been 
found to be some of the most commonly used in the literature on chemical oxidation of carbon materials [14-19].

The nomenclature employed for the chemically-modified samples involves the letter referring to the commercial $\mathrm{AC}(\mathrm{W})$; the letters $\mathrm{N}, \mathrm{H}$ or $\mathrm{S}$ indicating the used oxidizing agent $\left(\mathrm{HNO}_{3}, \mathrm{H}_{2} \mathrm{O}_{2}\right.$ and $\left(\mathrm{NH}_{4}\right)_{2} \mathrm{~S}_{2} \mathrm{O}_{8}$, respectively); and finally, a number related to the concentration or the time of treatment $\left(23 \%, 35 \%\right.$ or $65 \%$ for $\mathrm{HNO}_{3} ; 10 \%, 20 \%$ or $33 \%$ for $\mathrm{H}_{2} \mathrm{O}_{2}$; and $2 \mathrm{~h}, 5 \mathrm{~h}$ or $24 \mathrm{~h}$ for $\left.\left(\mathrm{NH}_{4}\right)_{2} \mathrm{~S}_{2} \mathrm{O}_{8}\right)$.

\subsection{Characterization of the activated carbon.}

After the electrochemical and chemical oxidation experiments, and prior to their characterization, the AC samples were washed by soaking (24h) into successive portions of distilled water until constant $\mathrm{pH}$ was reached. Next, AC samples were filtered and dried at 110 ${ }^{\circ} \mathrm{C}$ overnight.

\subsubsection{Porous texture characterization}

The porous texture of all samples was determined by physical adsorption of gases $\left(\mathrm{N}_{2}\right.$ at $-196{ }^{\circ} \mathrm{C}$ and $\mathrm{CO}_{2}$ at $0{ }^{\circ} \mathrm{C}$ ) using an automatic adsorption system (Autosorb-6, Quantrachrome Corporation) after sample out-gassing at $250 \mathrm{C}$ under vacuum for $4 \mathrm{~h}$. Nitrogen adsorption at $-196{ }^{\circ} \mathrm{C}$ has been used for determining the total volume of micropores $\left(\mathrm{V}_{\mathrm{DR}}\left(\mathrm{N}_{2}\right)\right.$ ) (pore size smaller than $2 \mathrm{~nm}$ ), applying the Dubinin-Radushkevich (DR) equation, and for determining the specific surface area by the BET equation $\left(\mathrm{S}_{\mathrm{BET}}\right) . \mathrm{CO}_{2}$ adsorption at $0{ }^{\circ} \mathrm{C}$ has been used to assess the narrowest micropores $\left(\mathrm{V}_{\mathrm{DR}}\left(\mathrm{CO}_{2}\right)\right)$ (pore size smaller than around $0.7 \mathrm{~nm}$ ), also by application of the Dubinin-Radushkevich theory [37-39]. 


\subsubsection{Surface chemistry characterization}

The characterization of SOGs present in $\mathrm{AC}$ has been done by Temperature Programmed Desorption (TPD) experiments, using a DSC-TGA equipment (TA Instruments, SDT 2960 Simultaneous) coupled to a mass spectrometer (Thermostar, Balzers, MSC 200). In these experiments, about $20 \mathrm{mg}$ of the sample were heated up to $950{ }^{\circ} \mathrm{C}$ (heating rate $20^{\circ} \mathrm{C} / \mathrm{min}$ ) under a helium flow rate of $100 \mathrm{~mL} / \mathrm{min}$.

\section{Results and Discussion}

\subsection{Influence of applied current and anode material in the anodic oxidation of $\mathrm{AC}$ in $\mathrm{NaCl}$}

Figure 1 shows the $\mathrm{CO}_{2}$ and $\mathrm{CO}$ TPD profiles obtained for AC samples treated anodically in 2 $\mathrm{wt} \% \mathrm{NaCl}$ at different applied current for $3 \mathrm{~h}$, with different anodes, and those obtained for the untreated (original) $\mathrm{AC}$ sample. Table 1 summarizes the quantification of the $\mathrm{CO}$ and $\mathrm{CO}_{2}$ evolved in these TPD experiments, the $\mathrm{CO} / \mathrm{CO}_{2}$ ratios and the total oxygen content $(\mathrm{O})$, which has been calculated from the evolved $\mathrm{CO}$ and $\mathrm{CO}_{2}$. Table 1 also shows quantification data for AC samples treated anodically for 1 and $5 \mathrm{~h}$ using a Ti/ $\mathrm{RuO}_{2}$ anode. The corresponding TPD profiles are shown in Fig. 2.

The characterization of the surface chemistry of the original AC (W) shows a low concentration of SOGs (Table 1), particularly of the most acidic ones, such as carboxylic and phenolic groups, which decompose at lower temperatures (see TPD profiles in Figure 1). These chemical features are in agreement with the basicity $\left(\mathrm{pH}_{\mathrm{PZC}}=9\right)$ of this carbon material, in which the basic character of graphitic basal planes may predominate. 
As shown in Figures 1-2 and Table 1, the anodic treatment in $\mathrm{NaCl}$ with the different tested anodes remarkably increases the amount of both the $\mathrm{CO}_{2}$ - and the $\mathrm{CO}$-evolving surface groups. As a result, the total surface oxygen amount $(\mathrm{O})$ increases and therefore, the original GAC is oxidized to a considerable extent. Moreover, an increase in the applied current induces an increase in the oxidation degree of the activated carbons in all the current range investigated, regardless of the anode nature. As it has been previously proposed [30], the observed oxidation of the AC may arise from a combination of two processes: i) a direct anodic oxidation of the carbon particles owing to the positive potential reached at the anode and ii) an indirect oxidation process by electrogenerated chlorine species. It is well known that the electrochemical oxidation of chloride ions yields a series of highly oxidizing chlorine species such as free chlorine, hypochlorous acid and hypochlorite ions according to the following reactions $[40,41]$ :

Anode surface: $\quad 2 \mathrm{Cl}^{-} \rightarrow \mathrm{Cl}_{2}+2 \mathrm{e}^{-}$

Bulk solution: $\quad \mathrm{Cl}_{2}+\mathrm{H}_{2} \mathrm{O} \rightarrow \mathrm{HClO}+\mathrm{H}^{+}+\mathrm{Cl}^{-}$

$$
\mathrm{HClO} \rightarrow \mathrm{H}^{+}+\mathrm{ClO}^{-}
$$

These reactions have been reported to dominate over the oxidation of water via intermediate adsorbed hydroxyl radicals on $\mathrm{Ti} / \mathrm{Pt},[42], \mathrm{Ti} / \mathrm{PbO}_{2}$ [43], $\mathrm{Ti} / \mathrm{IrO}_{2}$ [44], and Ti-based DSA anodes made of mixed transition metal oxides $[40,41]$ in $\mathrm{NaCl}$ solutions. In accordance with the literature data we will assume that the second mechanism is the preferred one for the oxidation of AC samples in this work.

The $\mathrm{CO}_{2}$ and $\mathrm{CO}$ profiles of GAC samples anodically-treated with different anodes and at different currents or electrolysis time (Figures 1-2) are similar in shape, suggesting that, although different in concentration, the SOGs introduced onto the GAC after the electrochemical 
treatment in $\mathrm{NaCl}$ are of the same nature for all anode materials. Nevertheless, there are some distinct features that should be noted regarding the evolution of the $\mathrm{CO}_{2}$ peak associated with the most stable lactone groups. A slight to negligible increase in this type of groups is observed upon increasing current in electrolysis performed with $\mathrm{Ti} / \mathrm{RuO}_{2}$ and $\mathrm{Ti} / \mathrm{Pt}$ anodes. On the contrary, the lactone peak decreases when the electrochemical treatment is done at $\mathrm{Ti} / \mathrm{Co}_{3} \mathrm{O}_{4}$ anodes. Finally, the GAC sample treated at a $\mathrm{SnO}_{2}$-based anode shows a general increase in all the acidic groups, especially carboxylic acid and lactone groups, and a lowering in the concentration of the latter at the highest electrolysis current.

The origin of the observed differences in the amount of surface oxygen groups and the TPD profiles are maybe due to the different electrode kinetics for the chloride electro-oxidation. Then, a more detailed analysis of individual contribution from specific surface oxygen groups in relation to the electrode used, could give a more accurate picture of the oxidation of the carbon surface. This kind of analysis is currently under preparation where deconvolution of the TPD profiles according to the procedure described by other authors will be used [45].

Figure 3 plots the increase in the amount of $\mathrm{CO}$ - and $\mathrm{CO}_{2}$-type surface oxygen groups with respect to the pristine $\mathrm{AC}$ versus the increase in the total amount of oxygen loaded on the carbon surface for both the electrochemical and chemical treatments. Figure $3 \mathrm{a}$ shows that the increments in the amount of both $\mathrm{CO}$ - and $\mathrm{CO}_{2}$-evolving groups grow linearly with the total oxygen incorporated on the carbon surface by anodic oxidation. Data points from electrolyses at different electrodes and input currents or treatment times (Table 1) fit fairly well to the same straight line. This linear dependence further supports our view that the characteristics of surface oxygen functionalities created by anodic treatment are not governed by the anode material, but they stem from the particular oxidation mechanism involving electrogenerated oxidizing species. 
In fact, TPD profiles for AC oxidized anodically in $\mathrm{H}_{2} \mathrm{SO}_{4}$ medium (cf. Fig.2b, Ref 30) appear rather different than those in Figs 1-2 and the corresponding data points in Fig.3a do not follow the same trend than those in $\mathrm{NaCl}$ medium. The linear variation exhibited in Fig 3a indicates that the surface oxide concentration grows in a uniform fashion in $\mathrm{NaCl}$ electrolyte, i.e., groups desorbing as $\mathrm{CO}$ and groups desorbing as $\mathrm{CO}_{2}$ grow at constant rate as the oxidation level increases, regardless of the anode material. This is probably a consequence of the fact that the electrochemical oxidation in $\mathrm{NaCl}$ electrolyte is mainly due to an indirect oxidation process through electrogenerated active chlorine species.

Unlike results reported by Barton and coworkers [27], the straight line in Fig 3a does not intercept the origin. Consequently, the $\Delta \mathrm{CO} / \Delta \mathrm{CO}_{2}$ ratio should change with the increasing oxidation level, instead of remaining constant. Parameters from linear fits in Fig 3a were used to predict $\Delta \mathrm{CO} / \Delta \mathrm{CO}_{2}$ ratios in order to realize their variation with the increasing oxidation degree. Simulated $\Delta \mathrm{CO} / \Delta \mathrm{CO}_{2}$ ratios are plotted as a function of the increment in oxygen content in Fig. 4. This figure shows that high $\Delta \mathrm{CO} / \Delta \mathrm{CO}_{2}$ ratios are formed at low oxidation levels and a fast decay up to levelling off occurs as the amount of total oxygen increases.

The above results suggest that similar oxidation levels with similar composition of the surface oxygen groups can be achieved with different types of anode by anodic treatment in $\mathrm{NaCl}$, provided that adequate selection of electrolysis current and time is made. The different performances of the anode materials must be then analyzed in terms of Faradaic oxidation efficiency. The average oxidation efficiency $(\varepsilon)$ for the electrochemical oxidation of AC can be derived from the amount of oxygen $(\mathrm{O})$ fixed for a given period of time according to the following equation: 


$$
\varepsilon=\frac{\left(\mathrm{O}_{\mathrm{f}}-\mathrm{O}_{\mathrm{i}}\right)}{\mathrm{It}}
$$

where $\mathrm{O}_{\mathrm{f}}$ and $\mathrm{O}_{\mathrm{i}}$ stand for the final and initial concentrations of oxygen in the carbon material after and before the electrochemical treatment, respectively; $I$ is the applied current and $t$ is the duration of electrolysis. The average oxidation efficiency $(\varepsilon)$ can be alternatively expressed as percentage of used current after multiplying eq. 4 by the mass of treated carbon $\left(\mathrm{m}_{\mathrm{c}}\right)$ and the theoretical charge consumed per mole of atomic oxygen, $2 \mathrm{~F}$ ( $\mathrm{F}$ being the Faraday constant):

$$
\varepsilon \%=2 \mathrm{Fm}_{\mathrm{c}} \frac{\left(\mathrm{O}_{\mathrm{f}}-\mathrm{O}_{\mathrm{i}}\right)}{\mathrm{It}}
$$

Efficiency percentage $(\varepsilon \%)$ values are also collected in Table 1 . The average oxidation efficiency yields values from nearly $50 \%$ for $\mathrm{RuO}_{2}$ at low input charges to ca. $10 \%$ for $\mathrm{Co}_{3} \mathrm{O}_{4}$ anodes.. Overall, efficiency data show that $\mathrm{Ti} / \mathrm{RuO}_{2}$ is the most efficient anode material for the generation of SOGs. This behaviour is most likely to be due to the well-known higher electrochemical oxidation efficiency of $\mathrm{Ti} / \mathrm{RuO}_{2}$-based anodes for the electrogeneration of active chlorine species in chloride-containing electrolytes. One should note that $\mathrm{RuO}_{2}$-based anodes are currently used in electrolyzers in the chlorine-alkali industry [46]. Barton et al. [27] reported an intermediate efficiency of $28 \%$ with platinised $\mathrm{Pt}$ anodes in $0.5 \mathrm{M} \mathrm{K}_{2} \mathrm{SO}_{4}$ at currents about ten times as low as those used in this work. Therefore, it appears that the electrochemical oxidation of AC performed under the conditions used in this work is comparatively more efficient than that carried out in ref. 27.

In the case of $\mathrm{Ti} / \mathrm{RuO}_{2}$ and $\mathrm{Ti} / \mathrm{Pt}$ electrodes, the average oxidation efficiency decreases with the applied current, whereas for $\mathrm{Ti} / \mathrm{SnO}_{2}-\mathrm{Sb}-\mathrm{Pt}$ and $\mathrm{Ti} / \mathrm{Co}_{3} \mathrm{O}_{4}$ electrodes the efficiency does not 
follow a clear trend with the increasing current. In all electrodes, the lowest efficiencies are nevertheless obtained at the highest current tested $(1.0 \mathrm{~A})$. These results can be explained considering that the efficiency of side reactions, like oxygen evolution reaction (OER), increases as the current increases.

Quantification of oxygen groups and values of the oxidation efficiency (Table 1) show that the amount of oxygen fixed after $5 \mathrm{~h}$ at $0.2 \mathrm{~A}(4570 \mu \mathrm{mol} / \mathrm{g})$ is similar to that achieved with the same electrode after $3 \mathrm{~h}$ at $0.5 \mathrm{~A}(4610 \mu \mathrm{mol} / \mathrm{g})$, but at higher efficiency. From a practical point of view, these results point out that in order to achieve a given oxidation degree, it is more efficient to carry out anodic oxidation experiments at low currents and longer electrolysis times than to employ higher currents for shorter periods of time.

From data in Table 1, it appears clear that the anodic treatment in $\mathrm{NaCl}$ produces a higher increase in the $\mathrm{CO}$-evolving groups than in the $\mathrm{CO}_{2}$-evolving groups, as evidenced by the achievement of $\mathrm{CO} / \mathrm{CO}_{2}$ ratios well above that of the untreated $\mathrm{AC}$ sample. Furthermore, data in Fig. 4 clearly point out that CO-evolving groups form predominantly at low oxidation levels, i.e at low passed charges, whereas a higher proportion of $\mathrm{CO}_{2}$-evolving groups develop at higher oxidation degrees (higher passed charges).

\subsection{Comparison between chemical and electrochemical oxidation of AC.}

For comparison purposes, conventional chemical oxidation treatments of the same AC material were carried out. Figure 5 shows the $\mathrm{CO}_{2}$ and $\mathrm{CO}$ TPD profiles obtained for the original GAC (W) and those of the GAC samples chemically-treated with different oxidizing chemicals. Table 2 summarizes the quantification of the evolved $\mathrm{CO}_{2}$ and $\mathrm{CO}$ groups, the oxygen content $(\mathrm{O})$ and the $\mathrm{CO} / \mathrm{CO}_{2}$ ratio. 
TPD profiles (Figure 5) indicate that, under the present experimental conditions, chemical treatments with $\mathrm{HNO}_{3}$ and $\left(\mathrm{NH}_{4}\right)_{2} \mathrm{~S}_{2} \mathrm{O}_{8}$ lead to an increase in the amount of both types of SOGs ( $\mathrm{CO}$ and $\mathrm{CO}_{2}$-evolving groups), in the oxygen content $(\mathrm{O})$ and, consequently, cause the oxidation of the original GAC. On the contrary, the chemical treatment with $\mathrm{H}_{2} \mathrm{O}_{2}$ slightly increases the amount of $\mathrm{CO}$-evolving groups and the $\mathrm{CO}_{2}$-evolving groups remain almost unchanged.

According to other authors $[12,14,15,19]$, the use of $\mathrm{H}_{2} \mathrm{O}_{2}$ as an oxidizing agent of carbon materials produces a low oxidation degree, which seems to be independent of the peroxide concentration $[14,15]$. On the contrary, an increase in the oxidant concentration does bring about an increase in the $\mathrm{AC}$ oxidation degree when $\mathrm{HNO}_{3}$ is used in the chemical treatment [17].

When results of 2 h-treatments are considered, Figure 5 and Table 2 show that the chemical treatment with $\left(\mathrm{NH}_{4}\right)_{2} \mathrm{~S}_{2} \mathrm{O}_{8}$ produces the highest increase in the amount of SOGs of all three chemical treatments. Moreover, the oxidation degree produced by $\left(\mathrm{NH}_{4}\right)_{2} \mathrm{~S}_{2} \mathrm{O}_{8}$ increases with the time of treatment, reaching high values after $24 \mathrm{~h}[18,19]$.

The plot of the amount of generated $\mathrm{CO}$ - and $\mathrm{CO}_{2}$-evolving groups versus the oxidation level (Fig. 3b) indicates that the overall stoichiometry of the SOGs is rather different for all three chemical treatments and also distinct from the composition of the surface oxides obtained by electrochemical treatment, because $\mathrm{CO}$ - and $\mathrm{CO}_{2}$-desorbing groups develop at rather different rates with the increasing oxidation degree. As to the evolution of the $\Delta \mathrm{CO} / \Delta \mathrm{CO}_{2}$ ratio, Fig 4 also shows marked differences in the behaviour of the three chemical oxidation methods treated in this work. The chemical oxidation by $\mathrm{HNO}_{3}$ yields surface oxygen functionalities with an 
increasing predominance of groups that desorb as CO. Instead, a chemical treatment with $\mathrm{H}_{2} \mathrm{O}_{2}$ or $\left(\mathrm{NH}_{4}\right)_{2} \mathrm{~S}_{2} \mathrm{O}_{8}$ shows a decrease in the $\Delta \mathrm{CO} / \Delta \mathrm{CO}_{2}$ ratio as the oxidation degree rises. The high initial $\Delta \mathrm{CO} / \Delta \mathrm{CO}_{2}$ values for $\mathrm{H}_{2} \mathrm{O}_{2}$ at mild conditions can be explained by the fact that $\mathrm{CO}_{2}-$ evolving groups are almost unaffected by the treatment, i.e. CO-type groups are mainly formed, in agreement with results reported by earlier authors [15]. If the peroxide concentration is raised, i.e. the oxidation conditions become stronger; the oxidation degree rises slightly but the $\Delta \mathrm{CO} / \Delta \mathrm{CO}_{2}$ ratio drops abruptly as a consequence of the formation of larger amounts of $\mathrm{CO}_{2}-$ evolving groups. Persulfate treatments show a tendency in the $\Delta \mathrm{CO} / \Delta \mathrm{CO}_{2}$ ratio that parallels that obtained for electrochemical oxidation, although with slightly lower values.

In the light of the observed changes in $\Delta \mathrm{CO} / \Delta \mathrm{CO}_{2}$ ratios, and considering the low content of SOGs in the original AC (see section 3.1.), it could be proposed that the oxidation of the studied carbon material by both anodic treatment and chemical oxidation with persulfate proceeds via formation of CO-evolving groups being fixed on free surface sites, in agreement with the increase in the $\Delta \mathrm{CO} / \Delta \mathrm{CO}_{2}$ ratio observed after any oxidation treatment, whereas $\mathrm{CO}_{2}$-evolving groups would be formed by oxidation of the existent or fresh CO-evolving groups, thus, justifying the decrease and eventual stabilization of the $\Delta \mathrm{CO} / \Delta \mathrm{CO}_{2}$ ratio at longer times of treatment or when the experimental conditions become stronger.

In general, from the comparison between results obtained with both electrochemical and chemical oxidation methods (Tables 1 and 2), it can be stated that for similar times of treatment (2-3 h) the anodic treatment in $\mathrm{NaCl}$ can produce oxidation degrees much higher than the chemical treatment with $\left(\mathrm{NH}_{4}\right)_{2} \mathrm{~S}_{2} \mathrm{O}_{8}$, which has been found to be the most oxidative chemical method studied in this work. Thus, after a 3 h-treatment, the most efficient anodes $\left(\mathrm{RuO}_{2}\right.$ and 
$\mathrm{SnO}_{2}-\mathrm{Sb}-\mathrm{Pt}$ ) produce at $0.5 \mathrm{~A}$ an oxidation degree similar to that obtained with $\left(\mathrm{NH}_{4}\right)_{2} \mathrm{~S}_{2} \mathrm{O}_{8}$ after $5 \mathrm{~h}$; and the oxidation degree achieved with $\mathrm{RuO}_{2}$ at $1.0 \mathrm{~A}$ is even higher than that of $\left(\mathrm{NH}_{4}\right)_{2} \mathrm{~S}_{2} \mathrm{O}_{8}$ after $24 \mathrm{~h}$. In addition, results in Figs. 3 and 4 suggest that the composition of the surface oxides formed by chemical oxidation with persulfate is the most similar one to that obtained after anodic oxidation.

According to the few reported studies on comparison between both methods [27], the electrochemical method in $0.5 \mathrm{M} \mathrm{K}_{2} \mathrm{SO}_{4}$ needed ca. 125 or $180 \mathrm{~h}$, at 50 o $30 \mathrm{~mA}$, respectively to achieve a similar oxidation degree than that produced with $6 \mathrm{M} \mathrm{HNO}_{3}, 2 \mathrm{~h}$ at $25{ }^{\circ} \mathrm{C}$,. The markedly low performance of the electrochemical method in that work can be easily explained considering the remarkably different experimental conditions employed by these authors, i.e., a predominant direct electrochemical oxidation in an inert electrolyte at low applied currents, which would give rise to much lower oxidation degrees.

\subsection{Influence of time on the anodic oxidation of $\mathrm{AC}$ in $\mathrm{NaCl}$ and by $\left(\mathrm{NH}_{4}\right)_{2} \mathrm{~S}_{2} \mathrm{O}_{8}$}

The influence of time of treatment on the surface chemistry of anodically-treated GAC samples was studied with the most oxidizing electrode, a $\mathrm{Ti} / \mathrm{RuO}_{2}$ anode, at $0.2 \mathrm{~A}$ (Table 1 ). As it can be seen, the rise in time of treatment progressively increases the amount of $\mathrm{CO}_{2}$ and CO-type SOGs. The SOGs generation rate can be followed as the increase in the amount of SOGs $\left(\mathrm{CO}, \mathrm{CO}_{2}\right.$ and O) with time of treatment. Such an increase in the number of SOGs can be calculated by subtraction of the amount of SOGs at a given time $\left(\mathrm{G}_{t}\right)$ minus the initial amount of SOGs $\left(\mathrm{G}_{0}\right)$.

Figure 6 depicts a comparison of the time-dependent amount of SOGs generated by electrochemical oxidation at $\mathrm{RuO}_{2}$ anodes and by chemical treatment with $\left(\mathrm{NH}_{4}\right)_{2} \mathrm{~S}_{2} \mathrm{O}_{8}$, since these are the most oxidizing conditions for each method. The generation rate of any kind of 
$\mathrm{SOG}_{\mathrm{i}}$ is related to the slope of the $\left(\mathrm{G}_{\mathrm{t}}-\mathrm{G}_{0}\right)_{\mathrm{i}}$ vs. time graph. For calculations, the amount of SOGs was normalized by the specific surface area $\left(\mathrm{S}_{\mathrm{BET}}\right)$ of the used original $\mathrm{AC}$. Results show that the generation rate of the different $\mathrm{SOGs}$ with $\left(\mathrm{NH}_{4}\right)_{2} \mathrm{~S}_{2} \mathrm{O}_{8}$ is faster at initial or shorter times (at least within the first $2 \mathrm{~h}$ ) and then, it decreases until the amount of surface groups levels off. On the contrary, the increase in SOGs with time by the anodic treatment at $0.2 \mathrm{~A}$, that is, the oxidation rate, is approximately constant with time, at least during the first $5 \mathrm{~h}$ of treatment. The observed tendencies in this preliminary kinetic study suggest that, unlike the chemical treatment, the anodic oxidation process in $\mathrm{NaCl}$ is amenable to a much more precise control owing to the observed linear dependence of the oxidation level and amount of SOGs with time. These results are attributed to the fact that, in the electrochemical treatment, the oxidizing species are supplied to the reaction medium at a constant rate determined by the applied current, most probably in the proximity of AC particles, whereas during the chemical oxidation with persulfate, the oxidizing species are in large excess from the beginning and remain nearly constant throughout the treatment.

The advantages of successfully controlling the oxidation degree by the electrochemical method were also underlined by Barton et al. [28]. However, these authors did not use an "active" electrolyte like $\mathrm{NaCl}$ and came to the conclusion that the electrochemical treatment spends much longer times than the chemical one to achieve similar oxidation degrees.

In spite of being a process initially (within the first 2-3 h) slower than the chemical treatment with $\left(\mathrm{NH}_{4}\right)_{2} \mathrm{~S}_{2} \mathrm{O}_{8}$, the anodic oxidation brings about higher $\Delta \mathrm{CO} / \Delta \mathrm{CO}_{2}$ ratios (see Fig 4). According to the proposed oxidation mechanism, the higher values in $\Delta \mathrm{CO} / \Delta \mathrm{CO}_{2}$ ratios suggest that the anodic oxidation produces comparatively a higher proportion of $\mathrm{CO}$-evolving groups. On the contrary, the lower $\Delta \mathrm{CO} / \Delta \mathrm{CO}_{2}$ ratios observed for the chemical oxidation (Fig. 4) reveal the 
generation of a higher relative proportion of $\mathrm{CO}_{2}$-evolving groups than in the case of anodic treatment, what points to a favoured oxidation attack near surface sites with bound oxygen and, therefore, a more aggressive and less controlled oxidation than that obtained during the electrochemical oxidation.

\subsection{Effect on textural properties of AC.}

Tables 3 and 4 summarize the main textural properties, such as the specific surface area $\left(\mathrm{S}_{\mathrm{BET}}\right)$, the total volume of micropores $\left(\mathrm{V}_{\mathrm{DR}}\left(\mathrm{N}_{2}\right)\right)$ and the narrowest micropores $\left(\mathrm{V}_{\mathrm{DR}}\left(\mathrm{CO}_{2}\right)\right)$, for the anodically- and chemically-treated AC samples under different experimental conditions and the untreated (original) activated carbon sample (W).

As it can be observed, and in agreement with previous results [30], the textural characterization shows that the anodic treatment in $\mathrm{NaCl}$ produce little modification of the porous texture of the activated carbon in the tested conditions (Table 4). The slight decrease in the textural parameters could be attributed to the increase in the SOGs concentration, which could hinder or block the adsorption of the employed gases during characterization. As it has been previously found $[15,20]$, this slight change in textural properties is also observed after the chemical treatments (Table 4), what seems to indicate that both oxidation processes mainly affect the surface chemistry of the used GAC.

\section{Conclusions}

Results have shown that the anodic treatment in $\mathrm{NaCl}$ with all the tested anodes causes a remarkable oxidation of the $\mathrm{AC}$ that progressively increases with the current and time of treatment. The similar shape of the TPD profiles of the electrochemically oxidized AC samples and the linear dependence of the amount of generated $\mathrm{CO}$ - and $\mathrm{CO}_{2}$-evolving groups with the 
increasing oxidation level suggests that the nature and composition of the anodically formed SOGs is not dependant on the anode nature, but it seems to be characteristic of electrolyses in $\mathrm{NaCl}$ medium. This result is consistent with an indirect homogeneous oxidation process, involving highly oxidizing chlorine species electrogenerated in the chloride-containing electrolyte. Moreover, a given oxidation level and composition of the oxygen groups can be achieved with any of the anodes studied, but at a very different Faradaic efficiency. Generally speaking, the faradic efficiency decreases as $\mathrm{Ti} / \mathrm{RuO} \mathrm{O}_{2}>\mathrm{Ti} / \mathrm{SnO}_{2}-\mathrm{Sb}-\mathrm{Pt}>\mathrm{Ti} / \mathrm{Pt}>\mathrm{Ti} / \mathrm{Co}_{3} \mathrm{O}_{4}$ in good correlation with the ability of each of these electrodes to generate bulk chlorine species.

Provided a proper input current is selected, the anodic treatment in $\mathrm{NaCl}$ can produce, during similar treatment times, much higher oxidation degrees in the $\mathrm{AC}$ than the conventional chemical treatments with $\mathrm{HNO}_{3}, \mathrm{H}_{2} \mathrm{O}_{2}$ or $\left(\mathrm{NH}_{4}\right)_{2} \mathrm{~S}_{2} \mathrm{O}_{8}$, this latter reagent being the most oxidative substance studied in this work. Neither the chemical nor the electrochemical treatments studied bring about a significant modification of the original porous texture of the studied AC.

The observed change in the $\Delta \mathrm{CO} / \Delta \mathrm{CO}_{2}$ ratio with the increasing oxidation level that applies to both the anodic treatment and the oxidation by persulfate supports an oxidation path in which CO-evolving groups are fixed on free sites, and $\mathrm{CO}_{2}$-evolving groups arise from oxidation of pre-existent or freshly formed CO-evolving groups. The lower values of the $\Delta \mathrm{CO} / \Delta \mathrm{CO}_{2}$ ratio for the chemical treatment with persulfate indicate that the oxidation of surface-oxidized sites is favoured in comparison to the anodic treatment, which seems to promote the oxidation of free surface sites instead. Another difference that should be highlighted is that the SOG generation rate in the anodically oxidized $\mathrm{AC}$ is constant in the timespan explored, whereas it is initially faster for the AC treated with persulfate and slows down progressively with increasing time until stabilization of the amount of surface groups. 
The results reported in this work give credit to the electrochemical treatment in $\mathrm{NaCl}$ electrolyte as an efficient and easily controllable technology for the modification of the surface chemistry of activated carbons.

\section{Acknowledgements}

Financial support by the Ministerio de Ciencia e Innovación (MAT2010-15273 and CTQ200910813) and Generalitat Valenciana and FEDER (PROMETEO/2009/047) projects are gratefully acknowledged.

\section{References}

[1] Puri BR. Surface complexes on carbons. In: Walker Jr PL, editor. Chemistry and physics of carbon, vol 6, New York; Marcel Dekker; 1970, p. 191-282.

[2] Bandosz TJ, Ania CO. Surface chemistry of activated carbons and its characterization. In: Bandosz TJ, editor. Activated Carbon Surfaces in Environmental Remediation, Elsevier; 2006, p. 159-230.

[3] Boehm HP. Surface oxides on carbon and their analysis: a critical assessment. Carbon 2002;40(2):145-149.

[4] Burg P, Cagniant D. Characterization of Carbon Surface Chemistry. In: Radovic LR, editor. Chemistry and physics of carbon, vol 30, Taylor \& Francis (CRC Press); 2008, p. 129-175.

[5] Leon y Leon CA, Radovic LR. Interfacial chemistry and electrochemistry of carbon surfaces. In: Thrower PA, editor. Chemistry and physics of carbon, vol 24, New York; Marcel Dekker; 1994, p. 213-310.

[6] Rodriguez-Reinoso F. The role of carbon materials in heterogeneous catalysis. Carbon 1998;36:159175. 
[7] Miyake M. Electrochemical Functions. In: Yasuda E, Inagaki M, Kaneko K, Endo M, Oya A, Tanabe Y, editors. Carbon alloys. Novel concepts to develop carbon science and technology, Elsevier Science; Amsterdam; 2003, p. 435-445.

[8] Carrasco-Marin F, Mueden A, Stoeckli F. Water adsorption on activated carbons with different degrees of oxidation. J Chem Soc Faraday Trans I 1997;93(12):2211-2215.

[9] Frackowiak E, Béguin F. Carbon materials for the electrochemical storage of energy in capacitors Carbon 2001;39(6):937-950.

[10] Bleda-Martínez MJ, Maciá-Agulló JA, Lozano-Castelló D, Morallón E, Cazorla-Amorós D. LinaresSolano A. Role of surface chemistry on electric double layer capacitance of carbon materials. Carbon 2005;43(13):2677-2684.

[11] Kamat PV. Graphene-Based Nanoarchitectures. Anchoring Semiconductor and Metal Nanoparticles on a Two-Dimensional Carbon Support. J Phys Chem Lett 2010;1(2):520-527.

[12] Linares-Solano A, Salinas-Martínez de Lecea C, Cazorla-Amorós D. Nature and Structure of Calcium Dispersed on Carbon. Energy Fuels 1990;4(5):467-474.

[13] Román-Martínez MC, Cazorla-Amorós D, Linares-Solano A, Salinas-Martínez de Lecea C. TPD and TPR characterization of carbonaceous supports and Pt/C catalysts. Carbon 1993;31(6):895-902.

[14] Domingo-Garcia M, Garzón FJL, Pérez-Mendoza MJ. On the characterization of chemical surface groups of carbon materials. J Colloid Interf Sci 2002;248(1):116-122.

[15] de Miguel SR, Scelza OA, Román-Martínez MC, Salinas-Martínez de Lecea C, Cazorla-Amorós D, Linares-Solano A. States of $\mathrm{Pt}$ in $\mathrm{Pt} / \mathrm{C}$ catalyst precursors after impregnation, drying and reduction steps. Appl Catal A 1998;170(1):93-103.

[16] Cheng PZ, Teng $\mathrm{H}$. Electrochemical responses from surface oxides present on $\mathrm{HNO}_{3}$-treated carbons. Carbon 2003;41(11):2057-2063.

[17] García T, Murillo R, Cazorla-Amorós D, Mastral AM, Linares-Solano A. Role of the activated carbon surface chemistry in the adsorption of phenanthrene. Carbon 2004;42(8-9):1683-1689. 
[18] Moreno-Castilla C, Carrasco-Marin F, Mueden A. The creation of acid carbon surfaces by treatment with $\left(\mathrm{NH}_{4}\right)_{2} \mathrm{~S}_{2} \mathrm{O}_{8}$. Carbon 1997;35(10-11):1619-1626.

[19] Moreno-Castilla C, Fero-García MA, Joly JP, Bautista-Toledo I, Carrasco-Marín F, Rivera-Utrilla J. Activated carbon surface modifications by nitric acid, hydrogen peroxide, and ammonium peroxydisulfate treatments. Langmuir 1995;11(11):4386-4392.

[20] Figueiredo JL, Pereira MFR, Freitas MMA, Orfao JJM. Modification of the surface chemistry of activated carbons. Carbon 1999;37(9):1379-1389.

[21] Álvarez PM, García-Araya JF, Beltrán FJ, Masa FJ, Medina F. Ozonation of activated carbons: Effect on the adsorption of selected phenolic compounds from aqueous solutions. J Colloid Interf Sci 2005;283(2):503-512.

[22] Pérez-Cadenas AF, Maldonado-Hódar FJ, Moreno-Castilla C. On the nature of surface acid sites of chlorinated activated carbons. Carbon 2003;41(3):473-478.

[23] García AB, Martínez-Alonso A, León y León CA, Tascón JMD. Modification of the surface properties of an activated carbon by oxygen plasma treatment. Fuel 1998;77(6):613-624.

[24] Kyotani T. Control of pore structure in carbon. Carbon 2000;38(2):269-86.

[25] Ishifune M, Suzuki R, Mima Y, Uchida K, Yamashita N, Kashimura S. Novel electrochemical surface modification method of carbon fiber and its utilization to the preparation of functional electrode. Electrochim Acta 2005;51(1):14-22.

[26] Shao YY, Yin GP, Zhang J, Gao YZ. Comparative investigation of the resistance to electrochemical oxidation of carbon black and carbon nanotubes in aqueous sulfuric acid solution. Electrochim Acta 2006;51(26):5853-5857.

[27] Barton SS, Evans MJB, Halliop E, MacDonald JAF. Anodic oxidaton of porous carbon. Langmuir 1997;13(5):1332-1336.

[28] Mehta MP, Flora JRV. Effects of electrochemical treatment of granular activated carbon on surface acid groups and the adsorptive capacity for phenol. Water Res 1997;31(9):2171-2176. 
[29] García-Otón M, Montilla F, Lillo-Ródenas MA, Morallón E, Vázquez JL. Electrochemical regeneration of activated carbon saturated with toluene. J Appl Electrochem 2005;35(3):319-325.

[30] Berenguer R, Marco-Lozar JP, Quijada C, Cazorla-Amoros D, Morallon E. Effect of electrochemical treatments on the surface chemistry of activation carbon. Carbon 2009;47(4):1018-1027.

[31] Yoon CM, Long D, Jang SM, Qiao W, Ling L, Miyawaki J et al. Electrochemical surface oxidation of carbon nanofibers. Carbon 2011;49(1):96-105.

[32] Bayram E, Ayranci E. A systematic study of the changes in properties of activated carbon cloth upon polarization. Electrochim Acta 2011;56(5):2184-2189.

[33] Bayram E, Ayranci E. Investigation of change in properties of activated carbon cloth upon polarization and of electrosorption of dye basic blue-7. Electrochim Acta 2010;48(6):1718-1730.

[34] Berenguer R, Quijada C, Morallón, E. Electrochemical Characterization of $\mathrm{SnO}_{2}$ Electrodes Doped with Ru and Pt. Electrochim Acta 2009;54(22):5230-5238.

[35] La Rosa-Toro A, Berenguer R, Quijada C, Montilla F, Morallón E, Vázquez JL. Preparation and Characterization of Copper-Doped Cobalt Oxide Electrodes. J Phys Chem B 2006;110(47):2402124029.

[36] Montilla F, Morallon E, Vázquez JL. Evaluation of the electrocatalytic activity of antimony-doped tin dioxide anodes toward the oxidation of phenol in aqueous solutions. J Electrochem Soc 2005;152(10):B421-B427.

[37] Lozano-Castelló D, Suárez-García F, Cazorla-Amorós D, Linares-Solano A. Porous texture of carbons. In: Beguin F, Frackowiak E, editors. Carbons for electrochemical energy storage and conversion systems, CRC Press; 2009, p. 115-162.

[38] Cazorla-Amorós D, Alcañiz-Monge J, Linares-Solano A. Characterization of activated carbon fibers by $\mathrm{CO}_{2}$ adsorption. Langmuir 1996;12(11):2820-2824.

[39] Cazorla-Amorós D, Alcañiz-Monge J, de la Casa-Lillo MA, Linares-Solano A. $\mathrm{CO}_{2}$ as an adsorptive to characterize carbon molecular sieves and activated carbons. Langmuir 1998;14(16):4589-4596. 
[40] Panizza M, Gerisola G. Electrochemical oxidation of 2-naphthol with in situ electrogenerated active chlorine. Electrochim Acta 2003;48(11):1515-1519.

[41] Rajkumar D, Kim JG, Palanivelu K. Indirect Electrochemical Oxidation of Phenol in the Presence of Chloride for Wastewater Treatment. Chem Eng Technol 2005;28(1):98-105.

[42] Bonfatti F, De Battisti A, Ferro S, Lodi G, Osti S. Anodic mineralization of organic substrates in chloride-containing aqueous media. Electrochim Acta 2000;46(2-3):305-314.

[43] Iniesta J, González-García J, Expósito E, Montiel V, Aldaz A. Influence of chloride ion on electrochemical degradation of phenol in alkaline medium using bismuth doped and pure $\mathrm{PbO}_{2}$ anodes Water Res 2001;35(14):3291-3300.

[44] Comninellis $\mathrm{Ch}$, Nerini A. Anodic oxidation of phenol in the presence of $\mathrm{NaCl}$ for wastewater treatment. J Appl Electochem 1995;25(1):23-28.

[45] Gorgulho HF, Mesquita JP, Gonçalves F, Pereira MFR, Figueiredo JL. Characterization of the surface chemistry of carbon materials by potentiometric tritations and temperature-programmed desorption. Carbon 2008; 46(12):1544-1555.

[46] Trasatti S. Progress in the understanding of the mechanism of chlorine evolution at oxide electrodes. Electrochim Acta 1987;32(3):369-382. 


\section{FIGURE CAPTIONS}

Figure 1. $\mathrm{CO}$ and $\mathrm{CO}_{2}$ evolution from TPD experiments for the original $\mathrm{AC}(\mathrm{W})$ and the anodically-treated $\mathrm{AC}$ samples in $2 \mathrm{wt} \% \mathrm{NaCl}$ for $3 \mathrm{~h}$ at different applied currents (A) using different anodes: (a) Ti/SnO 2 -Sb-Pt, (b) Ti/ $\mathrm{RuO}_{2}$, (c), $\mathrm{Ti} / \mathrm{Co}_{3} \mathrm{O}_{4}$ and (d) $\mathrm{Ti} / \mathrm{Pt}$.

Figure 2. $\mathrm{CO}$ and $\mathrm{CO}_{2}$ evolution from TPD experiments for the original $\mathrm{AC}(\mathrm{W})$ and the anodically-treated $\mathrm{AC}$ samples with a $\mathrm{Ti} / \mathrm{RuO}_{2}$ anode, at $0.2 \mathrm{~A}$, in $2 \mathrm{wt} \% \mathrm{NaCl}$ for different times.

Figure 3. Variation of the increment in the content $\mathrm{CO}$ - and $\mathrm{CO}_{2}$-evolving groups versus the increased oxidation degree for: (a) anodically-treated $\mathrm{AC}$ samples in: $2 \mathrm{wt} \% \mathrm{NaCl}$ at $\mathrm{Ti} / \mathrm{RuO}_{2}$ $(\diamond), \mathrm{Ti} / \mathrm{SnO}_{2}-\mathrm{Sb}-\mathrm{Pt}(\boldsymbol{\bullet}), \mathrm{Ti} / \mathrm{Co}_{3} \mathrm{O}_{4}(\boldsymbol{O})$ and $\mathrm{Ti} / \mathrm{Pt}(\boldsymbol{\Delta})$ anodes; in $0.5 \mathrm{M} \mathrm{H}_{2} \mathrm{SO}_{4}$ at $\mathrm{Ti} / \mathrm{SnO} 2-\mathrm{Sb}-\mathrm{Pt}$ $(\diamond)$ and $\mathrm{Ti} / \mathrm{Pt}(\Delta)$ anodes; (b) chemically-treated AC samples in $\mathrm{H}_{2} \mathrm{O}_{2}, \mathrm{HNO}_{3}$ and $\left(\mathrm{NH}_{4}\right)_{2} \mathrm{~S}_{2} \mathrm{O}_{8}$ solutions.

Figure 4. Simulated and experimental dependence of $\Delta \mathrm{CO} / \Delta \mathrm{CO}_{2}$ ratio on the oxidation level for anodically- and chemically-treated AC samples.

Figure 5. $\mathrm{CO}$ and $\mathrm{CO}_{2}$ evolution from TPD experiments for the original activated carbon (W) and the chemically-treated $\mathrm{AC}$ samples with (a) $\mathrm{HNO}_{3}$, (b) $\mathrm{H}_{2} \mathrm{O}_{2}$ and (c) $\left(\mathrm{NH}_{4}\right)_{2} \mathrm{~S}_{2} \mathrm{O}_{8}$ in different conditions. 
Figure 6. Time evolution of oxygen and different oxygen groups during chemical (Q$\left.\left(\mathrm{NH}_{4}\right)_{2} \mathrm{~S}_{2} \mathrm{O}_{8}\right)$ and electrochemical $\left(\mathrm{EQ}-\mathrm{RuO}_{2}\right)$ treatments $(2 \mathrm{wt} \% \mathrm{NaCl} \mathrm{I}=0.2 \mathrm{~A})$. 


\section{TABLE CAPTIONS}

Table 1. $\mathrm{CO}$ and $\mathrm{CO}_{2}$ evolved from TPD experiments, the total amount of oxygen $(\mathrm{O})$ and the $\mathrm{CO} / \mathrm{CO}_{2}$ ratio of the original $\mathrm{AC}(\mathrm{W})$ and the anodically-treated $\mathrm{AC}$ samples for $3 \mathrm{~h}$ in $2 \mathrm{wt} \%$ $\mathrm{NaCl}$ at different applied currents and with different anodes. $\varepsilon=$ electrochemical oxidation efficiency of AC.

Table 2. $\mathrm{CO}$ and $\mathrm{CO}_{2}$ evolved from TPD experiments, the total amount of oxygen $(\mathrm{O})$ and the $\mathrm{CO} / \mathrm{CO}_{2}$ ratio of the original $\mathrm{AC}(\mathrm{W})$ and the chemically-treated $\mathrm{AC}$ samples with $\mathrm{HNO}_{3}, \mathrm{H}_{2} \mathrm{O}_{2}$ and $\left(\mathrm{NH}_{4}\right)_{2} \mathrm{~S}_{2} \mathrm{O}_{8}$ in different conditions.

Table 3. Textural characterization of the original AC (W) and the anodically-treated AC samples in $2 \mathrm{wt} \% \mathrm{NaCl}$ under different experimental conditions.

Table 4. Textural characterization of the original AC (W) and the chemically-treated AC samples with $\mathrm{HNO}_{3}, \mathrm{H}_{2} \mathrm{O}_{2}$ and $\left(\mathrm{NH}_{4}\right)_{2} \mathrm{~S}_{2} \mathrm{O}_{8}$ in different conditions. 
Table 1

\begin{tabular}{|c|c|c|c|c|c|c|}
\hline Sample & $\begin{array}{c}\mathrm{CO} \\
\mu \mathrm{mol} \mathrm{g}\end{array}$ & $\begin{array}{c}\mathrm{CO}_{2} \\
\mu \mathrm{mol} \mathrm{g}^{-1}\end{array}$ & $\begin{array}{c}\mathrm{O} \\
\mu \mathrm{mol} \mathrm{g}^{-1}\end{array}$ & $\operatorname{\mu mol}^{\varepsilon} \mathrm{g}^{-1} \mathrm{C}^{-1}$ & $\varepsilon(\%)$ & $\mathrm{CO} / \mathrm{CO}_{2}$ \\
\hline W & 418 & 393 & 1204 & --- & --- & 1.06 \\
\hline $\mathrm{WSnO}_{2} \mathrm{a} 0.2 \mathrm{Cl}^{-}(3 \mathrm{~h})$ & 1320 & 643 & 2606 & 0.65 & 25.0 & 2.05 \\
\hline $\mathrm{WSnO}_{2} \mathrm{a}_{0.5 \mathrm{Cl}^{-}}(3 \mathrm{~h})$ & 2370 & 1340 & 5050 & 0.71 & 27.4 & 1.77 \\
\hline $\mathrm{WSnO}_{2}$ a1.0 $\mathrm{Cl}^{-}(3 \mathrm{~h})$ & 2800 & 1570 & 5940 & 0.44 & 16.8 & 1.78 \\
\hline $\mathrm{WRuO}_{2} \mathrm{a} 0.2 \mathrm{Cl}^{-}(1 \mathrm{~h})$ & 1280 & 443 & 2166 & 1.34 & 51.6 & 2.89 \\
\hline $\mathrm{WRuO}_{2} \mathrm{a} 0.2 \mathrm{Cl}^{-}(3 \mathrm{~h})$ & 1700 & 793 & 3286 & 0.96 & 37.2 & 2.14 \\
\hline $\mathrm{WRuO}_{2} \mathrm{a} 0.2 \mathrm{Cl}^{-}(5 \mathrm{~h})$ & 2350 & 1110 & 4570 & 0.93 & 36.0 & 2.12 \\
\hline $\mathrm{WRuO}_{2} \mathrm{a} 0.5 \mathrm{Cl}^{-}(3 \mathrm{~h})$ & 2270 & 1170 & 4610 & 0.63 & 24.0 & 1.94 \\
\hline $\mathrm{WRuO}_{2}$ a1.0 $\mathrm{Cl}^{-}(3 \mathrm{~h})$ & 3270 & 1760 & 6790 & 0.52 & 20.0 & 1.86 \\
\hline $\mathrm{WCo}_{3} \mathrm{O}_{4} \mathrm{a} 0.2 \mathrm{Cl}^{-}(3 \mathrm{~h})$ & 979 & 376 & 1731 & 0.24 & 9.4 & 2.60 \\
\hline $\mathrm{WCo}_{3} \mathrm{O}_{4} \mathrm{a} 0.5 \mathrm{Cl}^{-}(3 \mathrm{~h})$ & 1630 & 800 & 3230 & 0.38 & 14.4 & 2.04 \\
\hline $\mathrm{WCo}_{3} \mathrm{O}_{4}$ a1.0 $\mathrm{Cl}^{-}(3 \mathrm{~h})$ & 2290 & 1160 & 4610 & 0.32 & 12.2 & 1.97 \\
\hline $\mathrm{WTi} / \mathrm{Pt}$ a0.2 $\mathrm{Cl}^{-}(3 \mathrm{~h})$ & 1510 & 736 & 2982 & 0.82 & 31.8 & 2.05 \\
\hline $\mathrm{WTi} / \mathrm{Pt} \mathrm{a} 0.5 \mathrm{Cl}^{-}(3 \mathrm{~h})$ & 1750 & 851 & 3452 & 0.42 & 16.0 & 2.06 \\
\hline WTi/Pt a $1.0 \mathrm{Cl}^{-}(3 \mathrm{~h})$ & 2620 & 1360 & 5340 & 0.38 & 14.8 & 1.93 \\
\hline
\end{tabular}

Table 2

\begin{tabular}{|ccccc|}
\hline Sample & $\begin{array}{c}\mathbf{C O} \\
\boldsymbol{\mu m o l} / \mathbf{g}\end{array}$ & $\begin{array}{c}\mathbf{C O}_{\mathbf{2}} \\
\boldsymbol{\mu m o l} / \mathbf{g}\end{array}$ & $\begin{array}{c}\mathbf{O} \\
\boldsymbol{\mu m o l} / \mathbf{g}\end{array}$ & $\mathbf{C O} / \mathbf{C O}_{\mathbf{2}}$ \\
\hline W & 418 & 393 & 1204 & 1.06 \\
\hline W-N-23\% & 1070 & 728 & 2526 & 1.47 \\
W-N-35\% & 1380 & 805 & 2990 & 1.71 \\
W-N-65\% & 1710 & 855 & 3420 & 2.00 \\
\hline W-H-10\% & 652 & 395 & 1442 & 1.65 \\
W-H-20\% & 729 & 402 & 1533 & 1.81 \\
W-H-33\% & 829 & 424 & 1677 & 1.96 \\
W-S-2h & 1870 & 1130 & 4130 & 1.65 \\
W-S-5h & 2070 & 1320 & 4710 & 1.57 \\
W-S-24h & 2630 & 1820 & 6270 & 1.45 \\
\hline
\end{tabular}


Table 3

\begin{tabular}{|c|c|c|c|}
\hline Sample & $\begin{array}{c}\mathrm{S}_{\mathrm{BET}} \\
\mathrm{m}^{2} \mathrm{~g}^{-1}\end{array}$ & $\begin{array}{l}V_{\mathrm{DR}}\left(\mathrm{N}_{2}\right) \\
\mathrm{cm}^{3} \mathrm{~g}^{-1}\end{array}$ & $\begin{array}{c}\mathrm{V}_{\mathrm{DR}}\left(\mathrm{CO}_{2}\right) \\
\mathrm{cm}^{3} \mathrm{~g}^{-1}\end{array}$ \\
\hline $\mathrm{W}$ & 875 & 0.37 & 0.29 \\
\hline $\mathrm{WSnO}_{2} \mathrm{a} 0.2 \mathrm{Cl}^{-}$ & 848 & 0.37 & 0.22 \\
\hline $\mathrm{WSnO}_{2} \mathrm{a} 0.5 \mathrm{Cl}^{-}$ & 769 & 0.34 & 0.23 \\
\hline $\mathrm{WSnO}_{2}$ a1.0 $\mathrm{Cl}^{-}$ & 775 & 0.35 & 0.30 \\
\hline $\mathrm{WRuO}_{2} \mathrm{a} 0.2 \mathrm{Cl}^{-}$ & 864 & 0.38 & 0.30 \\
\hline $\mathrm{WRuO}_{2} \mathrm{a} 0.5 \mathrm{Cl}^{-}$ & 792 & 0.35 & 0.28 \\
\hline $\mathrm{WRuO}_{2}$ a1.0Cl- & 740 & 0.33 & 0.27 \\
\hline $\mathrm{WRuO}_{2} \mathrm{a}_{0.2 \mathrm{Cl}^{-} 1 \mathrm{~h}}$ & 831 & 0.37 & 0.29 \\
\hline $\mathrm{WRuO}_{2} \mathrm{a} 0.2 \mathrm{Cl}^{-} 5 \mathrm{~h}$ & 783 & 0.34 & 0.28 \\
\hline $\mathrm{WCo}_{3} \mathrm{O}_{4} \mathrm{a} 0.2 \mathrm{Cl}^{-}$ & 815 & 0.34 & 0.30 \\
\hline $\mathrm{WCo}_{3} \mathrm{O}_{4} \mathrm{a} 0.5 \mathrm{Cl}^{-}$ & 822 & 0.34 & 0.23 \\
\hline $\mathrm{WCo}_{3} \mathrm{O}_{4}$ a $1.0 \mathrm{Cl}^{-}$ & 735 & 0.32 & 0.27 \\
\hline $\mathrm{WTi} / \mathrm{Pt} \mathrm{a} 0.2 \mathrm{Cl}^{-}$ & 824 & 0.36 & 0.28 \\
\hline 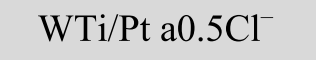 & 772 & 0.34 & 0.29 \\
\hline WTi/Pt a $1.0 \mathrm{Cl}^{-}$ & 810 & 0.35 & 0.29 \\
\hline
\end{tabular}

Table 4

\begin{tabular}{|cccc|}
\hline Sample & $\begin{array}{c}\mathbf{S}_{\mathbf{B E T}} \\
\mathbf{m}^{\mathbf{2}} \mathbf{g}^{-\mathbf{1}}\end{array}$ & $\begin{array}{c}\mathbf{V}_{\mathbf{D R}}\left(\mathbf{N}_{\mathbf{2}}\right) \\
\mathbf{c m}^{\mathbf{3}} \mathbf{g}^{-\mathbf{1}}\end{array}$ & $\begin{array}{c}\mathbf{V}_{\mathbf{D R}}\left(\mathbf{C O}_{\mathbf{2}}\right) \\
\mathbf{c m}^{\mathbf{3}} \mathbf{g}^{-\mathbf{1}}\end{array}$ \\
\hline W & 875 & 0.37 & 0.29 \\
\hline W-N-23\% & 840 & 0.38 & 0.29 \\
W-N-35\% & 865 & 0.37 & 0.28 \\
W-N-65\% & 835 & 0.35 & 0.28 \\
\hline W-H-10\% & 851 & 0.36 & 0.30 \\
W-H-20\% & 886 & 0.38 & 0.31 \\
W-H-33\% & 879 & 0.38 & 0.28 \\
\hline W-S-2h & 864 & 0.36 & 0.29 \\
W-S-5h & 884 & 0.38 & 0.29 \\
W-S-24h & 870 & 0.38 & 0.30 \\
\hline
\end{tabular}


Figure 1
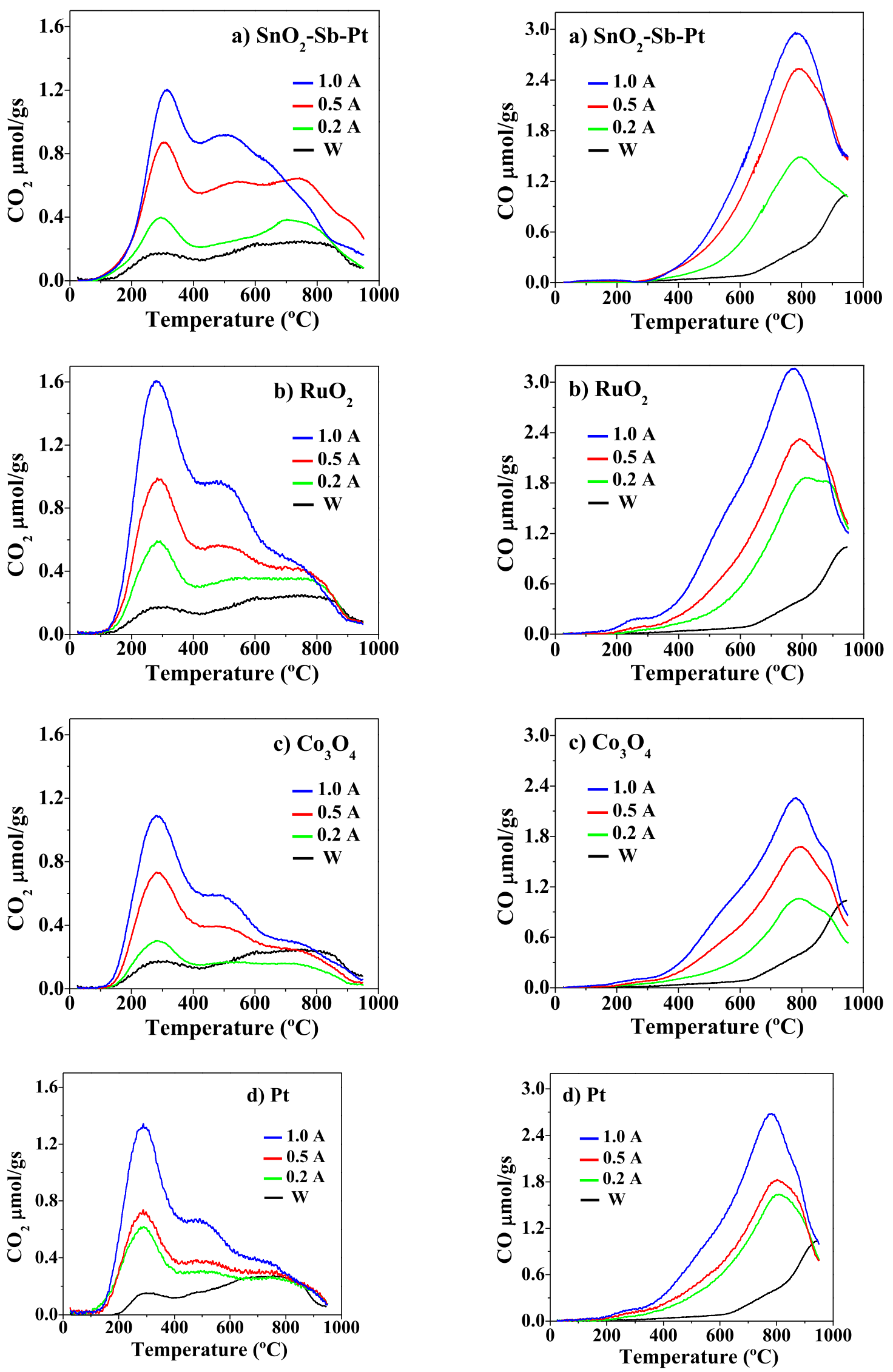
Figure 2
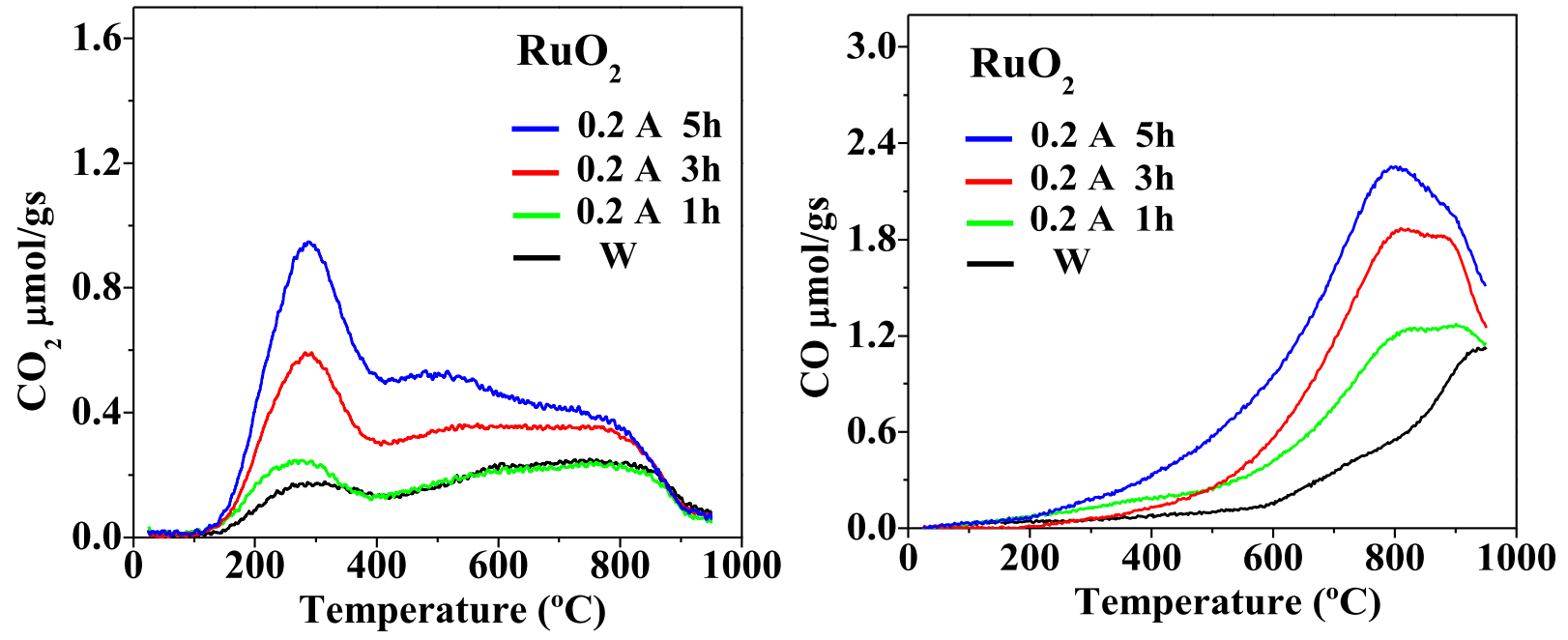
Figure 3
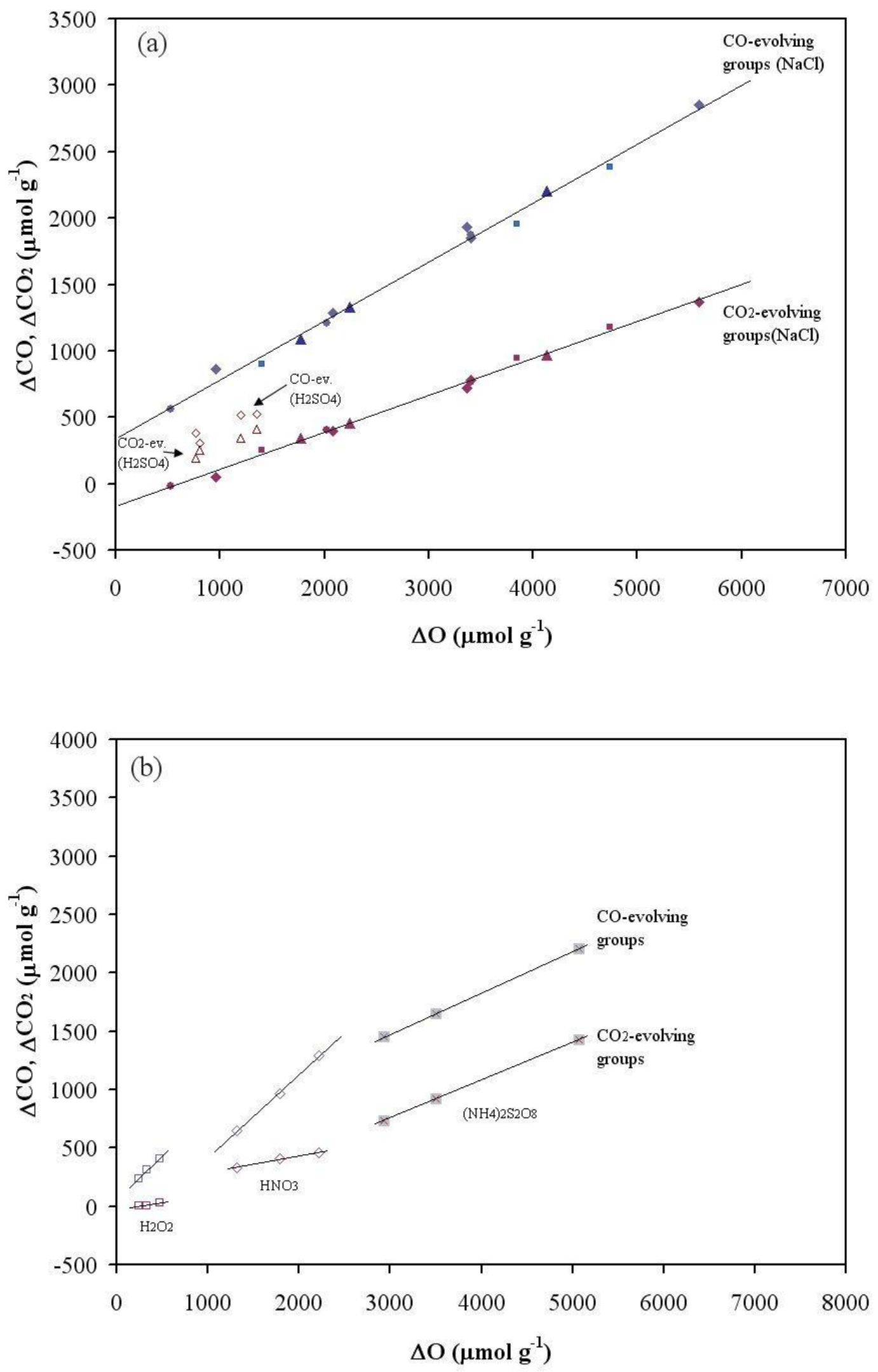
Figure 4

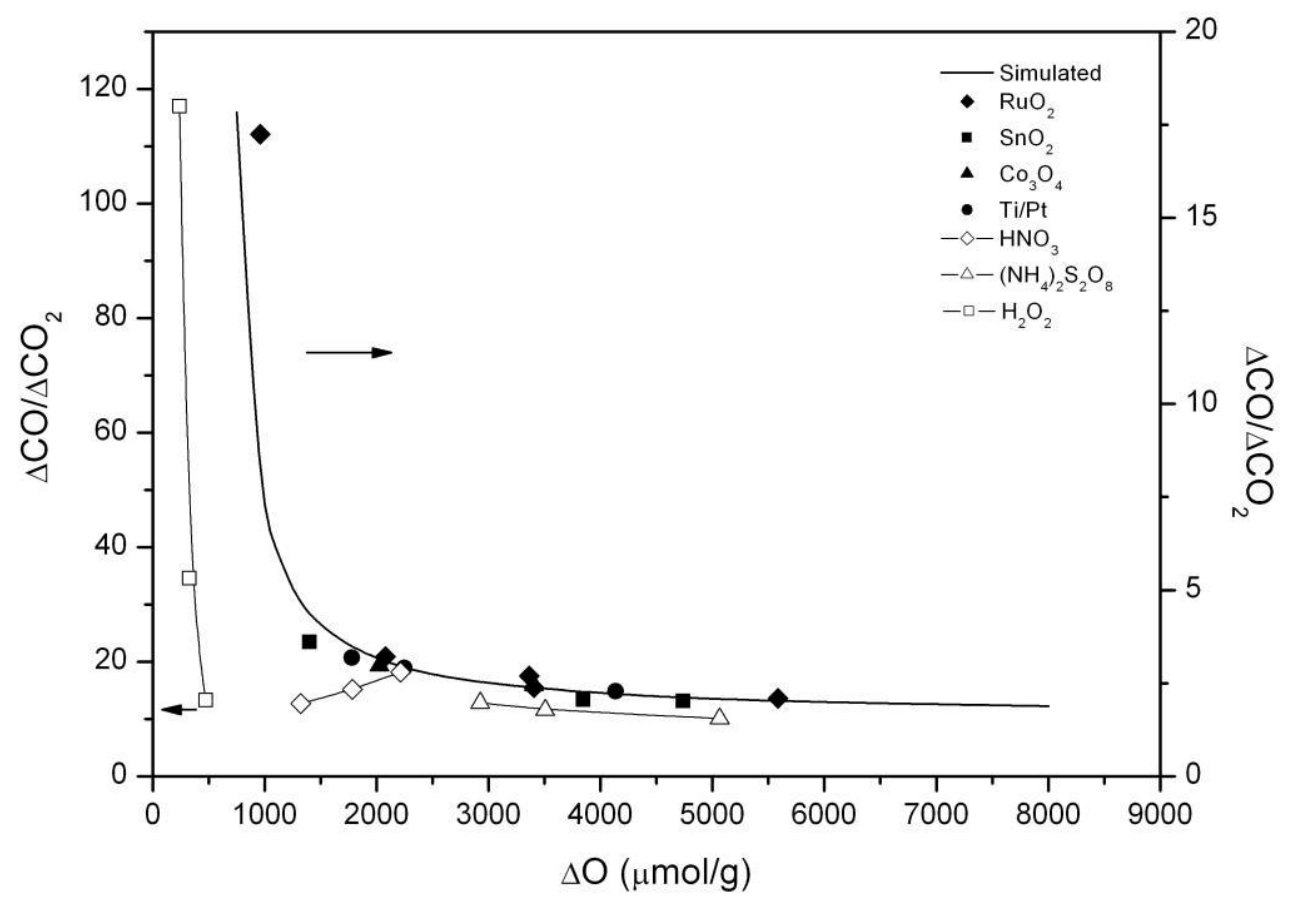


Figure 5
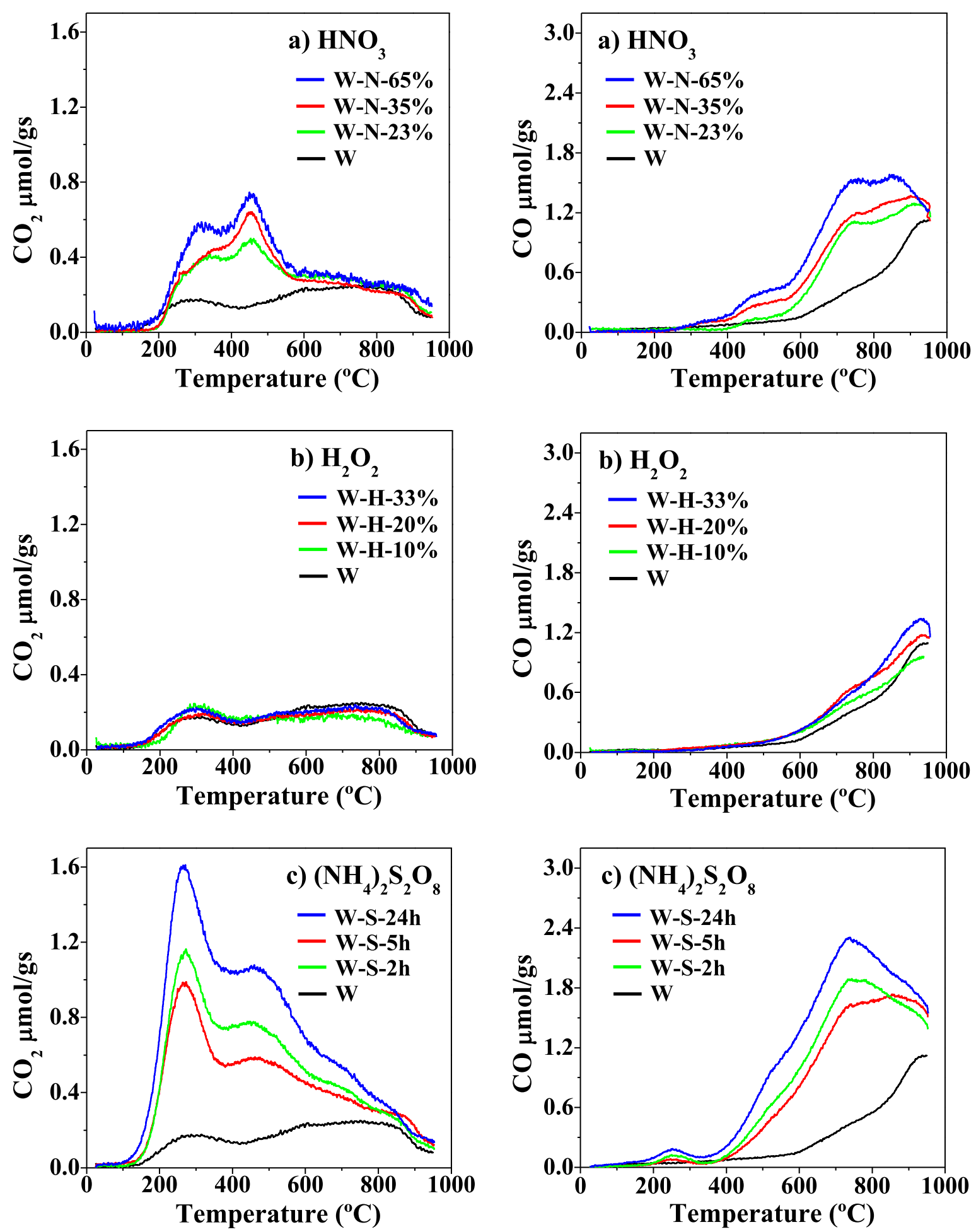
Figure 6

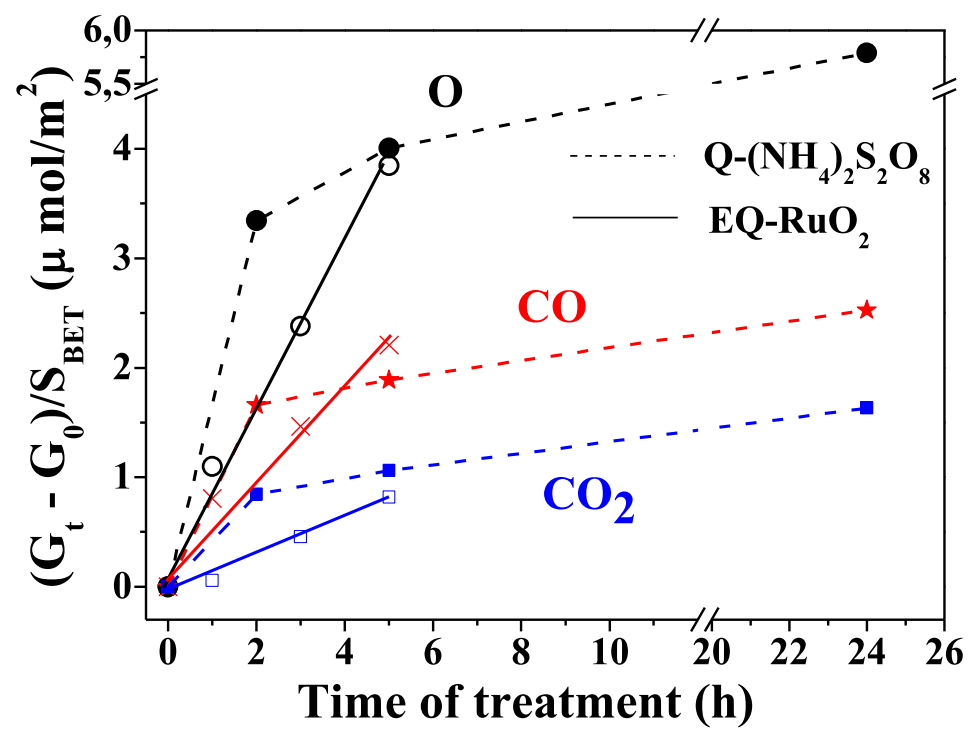

